\title{
Donativos, préstamos y privilegios. Los mercaderes y mineros de la ciudad de México durante la guerra anglo - española de 1779 - 1783
}

\author{
Álvaro Alcántara López \\ Centro INAH - Veracruz, México \\ guayamban@hotmail.com
}

Guillermina del Valle Pavón, Donativos, préstamos y privilegios. Los mercaderes y mineros de la ciudad de México durante la guerra anglo - española de 1779 - 1783, México, Instituto Mora, 2016, 227 pp.

Cuando en julio de 1779, la corona española le declaró la guerra a los ingleses, involucrándose en una nueva aventura militar iniciada por Francia, con el objeto de “apoyar” la lucha de los angloamericanos por liberarse de la sujeción británica, se detonaron una serie de procesos que vinieron a alterar los negocios de los novohispanos y las rutas del comercio global en la que éstos participaban, fungiendo como articuladores de las economías pacíficas y atlánticas a través de la plata americana. Del impacto y costo de esa guerra al erario español, de la participación de los mercaderes y mineros en el financiamiento del conflicto bélico, de la apertura del comercio novohispano al comercio asiático y de los beneficios que obtuvieron las ricas y poderosas familias de la Nueva España en el apuntalamiento de la hacienda real en los convulsivos años de 1776 a 1783, nos habla en su más reciente libro Guillermina del Valle.

\section{(c) (i) (s)}

No-Comercial 4.0 Internacional.

Secuencia. E-ISSN 2395-8464 http://secuencia.mora.edu.mx/

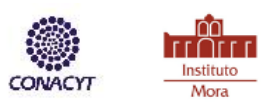


El objetivo de este trabajo nos lo deja muy claro la autora: "Analizar los mecanismos por los que la corona extrajo grandes contribuciones extraordinarias de la economía novohispana para fortalecer la Real Armada y solventar los gastos de la guerra anglosajona de 1779 - 1783.” Para ello se examina el papel otorgado por la corona a los cuerpos de comercio y minería con el propósito de que contribuyeran con recursos adicionales para fortalecer la Real Armada y, una vez declarada la guerra, para sostener las campañas bélicas que se emprendieron contra los británicos.

El libro Donativos, préstamos y privilegios se compone de tres apartados y una conclusión, además de una muy útil introducción, que permite comprender mejor la coyuntura histórica estudiada y aproximarse al debate historiográfico en torno al papel de los donativos de particulares y corporaciones en la economía imperial. En el primero apartado "Donativos para financiar la armada y el conflicto bélico" se abordan los distintos donativos realizados por los novohispanos para financiar al erario real en general y a la armada en particular, poniendo especial interés en aquellos realizados por el Consulado de comerciantes de la ciudad de México y el gremio minero desde 1775 - 1776 hasta ya bien iniciada la guerra de 1779 - 1783, así como las contraprestaciones que las élites económicas obtuvieron de la corona por las donaciones y empréstitos realizados. La decisiva participación de la corporación mercantil en estas recaudaciones la explica Guillermina del Valle en el marco de una pugna al interior del Consulado por la elección del cargo de Prior, la cual puso al descubierto la existencia de sobrantes de alcabalas administradas por los cónsules y priores en turno, por un monto que superaba el millón de pesos. Las desavenencias generadas por la existencia de este fondo provocaron tensiones entre el consulado y la corona que debieron ser arregladas y negociadas, 
siendo precisamente los donativos hechos por la corporación de comerciantes para evaluar la creación de posibles astilleros en la costa del Golfo y la construcción de navíos para fortalecer la armada, lo que permitió llegar a un arreglo conveniente y provechoso para ambas partes.

En la segunda sección "El libre comercio por el Pacífico Hispanoamericano 1774 1783, la autora aborda la apertura comercial del Pacífico novohispano en el periodo de 1774 a 1783, ofreciendo interesantes pistas del negocio triangular encabezado por los novohispanos, intercambiando textiles asiáticos, cacao ecuatoriano y plata novohispana y neo granadina, aprovechando favorablemente, el permiso otorgado por la corona para comerciar libremente con los puertos hispanoamericanos del Pacífico, tras la paralización del comercio atlántico ocasionado por la propia situación bélica y los constantes bloqueos de los ingleses a los puertos hispanoamericanos. Como se documenta en el trabajo, los comerciantes que mejor parecen haber aprovechado los beneficios de la apertura comercial por el Pacífico, fueron precisamente aquellos que contribuyeron significativamente con donaciones para aliviar a la afligida hacienda real, entre los que destacan los bien conocidos comerciantes Francisco Ignacio de Yraeta e Isidro Antonio de Icaza.

El tercer apartado "Suplementos, empréstitos y contraprestaciones" se enfoca, en cambio, en hacer un recuento pormenorizado de los recursos extraordinarios solicitados por el virrey Mayorga para socorrer las necesidades financieras de Cuba entre 1782 y 1783, dado el importante papel que jugaba esta isla en la geopolítica imperial y el comercio internacional. Para ello, Valle Pavón reconstruye las aportaciones que los comerciantes y mineros residentes en la ciudad de México otorgaron ante esta nueva petición, logrando reunir la impresionante cantidad de 1315000 pesos. Bajo esa misma estrategia, el virrey Mayorga logró reunir de comerciantes de España, por medio de sus representantes la suma de 408000 pesos. Como Secuencia. E-ISSN 2395-8464 
lo sugiere la autora, la "buena" disposición de estos comerciantes puede comprenderse en el marco de una política pactista en donde la construcción de confianza, el manejo de información privilegiada y la obtención de privilegios resultan fundamentales para comprender el mundo de los negocios.

Al colocar la atención en los "donativos" y "privilegios" de las élites económicas novohispanas de fines del siglo XVIII, Valle Pavón coloca su investigación en una trayectoria que lleva a problematizar los fundamentos mismos de la construcción del poder en el Antiguo Régimen. En ese sentido, la información que aporta lleva a cuestionar las visiones idealizadas del mundo de los negocios que ha querido resaltar excesivamente - en mi opinión - el carácter emprendedor de los poderosos comerciantes novohispanos, para en cambio, documentar los beneficios del capital relacional, así como las contraprestaciones y beneficios que se obtienen para desplegar los negocios al interior del virreinato y a lo largo y ancho del imperio, cuando se ha apoyado económicamente a la corona en momentos de apremio, mostrando así que eran "fieles vasallos deseosos de aprovechar la oportunidad de manifestar su fidelidad y amor al Rey".

Si los ricos son ricos - podría estar uno tentado a sentenciar al terminar de leer este interesante libro - es porque en buena medida disponen de recursos económicos y capital relacional que los coloca en una situación más favorable respecto de otros. Pero sobre todo porque en el mundo en el que vivieron estos poderoso comerciantes y hacendados los privilegios se construyen socialmente a partir de la calidad, la pertenecía a redes familiares y grupal o en función de la mayor o menor cercanía con el poder político. El hecho que los donativos realizados hayan servido para obtener licencias para comerciar por el Pacífico, para 
internar mercaderías de Xalapa al interior del virreinato o para obtener un título nobiliario da cuenta de ello.

La crítica al carácter "absolutista” de la monarquía española se encuentra implícita a lo largo de los tres capítulos del libro, al mostrar en reiteradas ocasiones que para la obtención de recursos financieros y fiscales las autoridades recurrían a la negociación y, muy pocas veces, a la imposición; lo que en opinión de Guillermina del Valle, evidencia la naturaleza contra actual de la organización política imperial. El recuento del dinero y suplementos aportado por los novohispanos en los años finales de la década del setenta y principios de los años ochenta hace pensar en un debate persistente en la historiografía colonial reciente, respecto del estatus de “colonia”, de la Nueva España respecto de la península. El poder económico exhibido por los novohispanos obliga a repensar el esquema metrópoli-colonia que ha alentado buena parte de los estudios coloniales, aunque paradójicamente las cantidades aportadas para suplir las exigencias de España tanto como de las posesiones caribeñas no hagan sino mostrar el carácter extractivo del sistema colonial español.

Otro aspecto a resaltar de este trabajo son los elementos de análisis que aporta la autora para pensar una historia interconectada, global, de la economía de la época y del papel que en ella desempeñó la Nueva España: cacao, plata americana, efectos de China, textiles europeos y asiáticos fueron las mercancías que circularon del Pacífico al Atlántico novohispano y viceversa, a través de tupidas redes mercantiles que dieron forma y sustento a lo que ahora se acostumbra denominar "primera globalización económica”. En cualquier caso, vale recordar aquí que el trajín económico y circulación de mercancías de los que se habla en este libro se encuentra presente, además de los archivos, en la lírica popular que aún hoy se sigue cantando en los respetivos repertorios que alimentan los complejos festivos del bajío mexicano, las costas 
veracruzanas o la tierra caliente de los estados de Guerrero, Estado de México o Michoacán. Canela, sayas, malacós, chocolate, sedas, clavos (esencia), ojitos que brillan como la plata, bretañas o tafetanes han quedado inscritos en los repertorios de la música tradicional mexicana como correlato de una historia económica que Guillermina del Valle ha sabido construir en este libro.

En medio de tantos hombres la política y los negocios que aparecen en el libro llama la atención el papel desempeñado por Pedro Antonio de Cossío, como mediador entre el virrey Mayorga, los mercaderes y mineros para reunir los donativos extraordinarios. Cossío, pertenecía a una familia de comerciantes proveniente de Cantabria que, de acuerdo a lo que señala la autora, se establecieron en Veracruz a principios del siglo XVIII y para fines de ese siglo, la casa Cossío ya era una de las más importantes de aquel puerto. Las capacidades de mediación ejercidas por Pedro Antonio de Cossío (consolidadas por una larga trayectoria como funcionario en distintos ámbitos de la administración colonial) invitan a reflexionar sobre la importancia de los intermediarios entre el mundo de la política y los negocios. Y aunque Cossío estaba lejos de igualar a las fortunas de las grandes familias de mineros, comerciantes y ganaderos del reino, su trayectoria individual invita a reflexionar sobre los mecanismos de construcción y afianzamiento del poder, el manejo de información privilegiada y la construcción de la confianza en el mundo de Antiguo Régimen.

Cobijando la actuación de los hombres de negocios queda resaltado el peso específico de las distintas corporaciones civiles y religiosas, reiterando su importancia en la vida social, política y económica del virreinato. Además de los ya conocidos Tribunal de Minería y la Universidad de Mercaderes, el libro documenta el papel protagónico de los Cabildos 
eclesiásticos de Valladolid, Guadalajara y Durango o los Ayuntamientos de la ciudad de México, Orizaba y Veracruz, al momento de financiar y fortalecer la armada. Surgen entonces las interrogantes de cuáles fueron las contraprestaciones y recompensas que obtuvieron estos cuerpos tras auxiliar a la corona en momentos de necesidad, toda vez que el libro muestra la permisibilidad de la corona para tolerar, de manera "excepcional" en momentos de coyunturas bélicas o crisis financieras, aquello expresamente prohibido en la legislación. El problema que se presenta a la investigación es el de cómo interpretar las políticas de la corona española, su aplicación y obediencia por parte de los súbditos, en un periodo de transición (del XVIII al XIX) marcada por las guerras y la bancarrota del erario real.

Hace tiempo entendí que un libro vale por lo que hace pensar, por las otras nuevas investigaciones que puede ayudar a construir, a imaginar. El libro de Guillermina del Valle me ha hecho pensar en lo útil que sería desplegar aproximaciones prosopográficas, que permitan cruzar los nombres de los grandes comerciantes del consulado y reconstruir sus vínculos posibles con los comerciantes locales, alcalde, subdelegados, administradores de alcabalas o encargados de los reales estancos. Se me dirá con justicia que ese trabajo se ha hecho y, muy bien, por cierto. Sin embargo, habrá que decir que esto se ha hecho observando la circulación mercantil desde los intereses de los comerciantes capitalinos. Lo que imagino es precisamente una reflexión distinta, que situada en los espacios locales permita comprender los avatares de la vida económica y política local; los conflictos al interior de los pueblos de indios y mulatos, y de éstos con los grupos de poder en pueblos, villas y ciudades, a la luz de las exigencias de financiamiento que la corona puso sobre sus súbditos, en distintos niveles y escalas socio espaciales.

Secuencia. E-ISSN 2395-8464 
Si la riqueza generada por esta circulación mercantil es analizada exclusivamente a partir de los grandes almaceneros y, si los nombres de estos ricos novohispanos son desligados de sus familias y de las redes que los vinculaba con la dinámica social de los espacios locales, nuestra comprensión de cómo se construyeron el poder, la riqueza y el prestigio en la Nueva España seguirá siendo limitada.

El libro de Guillermina del Valle, Donativos, préstamos y privilegios contribuye desde la historia económica a volver a pensar éstos y otros problemas con mucho provecho y por eso me permito recomendar su lectura. 